\title{
Validation of the Greek version of the Adolescent Sleep Hygiene Scale (ASHS)
}

\author{
Vasiliki Efthymiou ${ }^{1}$, Dimitra Kotsikogianni ${ }^{2}$, Artemis K. Tsitsika ${ }^{3}$, Dimitrios Vlachakis ${ }^{1,4,5}$, George P. Chrousos ${ }^{1}$, \\ Evangelia Charmandari ${ }^{6}$, Flora Bacopoulou ${ }^{2} \sqrt{ }$
}

\begin{abstract}
${ }^{1}$ University Research Institute of Maternal and Child Health \& Precision Medicine and UNESCO Chair on Adolescent Health Care, First Department of Pediatrics, School of Medicine, National and Kapodistrian University of Athens, Athens, Greece

${ }^{2}$ Center for Adolescent Medicine and UNESCO Chair on Adolescent Health Care, First Department of Pediatrics, School of Medicine, National and Kapodistrian University of Athens, Aghia Sophia Children's Hospital, Athens, Greece

${ }^{3}$ Adolescent Health Unit, Second Department of Pediatrics, "P. \& A. Kyriakou" Children's Hospital, National and Kapodistrian University of Athens, Athens, Greece

${ }^{4}$ Laboratory of Genetics, Department of Biotechnology, School of Applied Biology and Biotechnology, Agricultural University of
\end{abstract} Athens, Athens, Greece

${ }^{5}$ Lab of Molecular Endocrinology, Center of Clinical, Experimental Surgery and Translational Research, Biomedical Research Foundation of the Academy of Athens, Athens, Greece

${ }^{6}$ Division of Endocrinology, Metabolism and Diabetes, First Department of Pediatrics, School of Medicine, National and Kapodistrian University of Athens, Aghia Sophia Children's Hospital, Athens, Greece

Competing interests: VE none; DK none; AKT none; DV none; GPC none, EC none; FB none

\section{Abstract}

Transition from childhood to adolescence is known to bring about many changes in the lifestyle and psychoemotional state of adolescents. One of the major lifestyle factors that affect adolescents' physical and mental health is sleep. The aim of this study was to validate the Adolescent Sleep Hygiene Scale (ASHS), a tool that measures sleep hygiene, in an adolescent sample living in Greece. The study's sample consisted of 146 Greek adolescents aged 12-18 years. The Adolescent Stress Questionnaire was used for convergent validity and correlation with adolescents' stress. The pilot and the main study demonstrated sufficient internal consistency. Exploratory Factor Analysis showed an adequate adaptation of the original ASHS questionnaire to the Greek adolescents. The findings of this study support the use of ASHS as a reliable and valid tool for evaluating sleep-facilitating and sleep-inhibiting practices of Greek adolescents.

\section{Introduction}

Sleep is an important process for a person's physical and mental health, development, learning, behaviour, emotional stability, and general functioning during the day. In terms of emotional balance, research on healthy people who sleep less than they need has shown that accumulation of sleep deprivation gradually leads to worsening of a person's mood (Talbot et al., 2010). The study of Yoo et al. in people with insufficient sleep due to an emotional stimulus, showed a $60 \%$ increase in amygdala activity compared to people who were relaxed (Yoo et al., 2007). This increased activity of the amygdala affects cognitive control and executive functions (Drummond et al., 1999; Muzur et al., 2002). The most common sleep disorders are those related to sleep apnea, insomnia, prolonged drowsiness, narcolepsy, restless legs syndrome / recurrent sleep syndrome extreme fatigue during the day, increased arousal before bedtime and nightmares (the difference with bad dreams is that the nightmare causes a sudden cessation of sleep and waking up at night) (Nielsen et al., 2000).

The transition from childhood to adolescence is known to bring about many changes in the lifestyle and psycho-emotional state of adolescents. One of the major lifestyle factors that affects adolescence is sleep. Adolescents tend to be late to sleep and want to stay up late, even on weekdays (Kirov et al.,2017). This seems to be due to delays in their circadian rhythm, studying, activities, many hours at the computer, as well as increased social life (Wang et al., 2016). As a person gets older, sleep needs change, especially in the transition from infancy to adolescence, where there is a dramatic change during both the daytime and nighttime sleep needs. For example, an infant needs about 17 hours, a teenager 8 hours and a middle-aged man 6.5

\section{Article history \\ Received: 1 December 2020 \\ Accepted: 24 December 2020 \\ Published: 22 October 2021}

() 2021 Efthymiou et al.; the authors have retained copyright and granted the Journal right of first publication; the work has been simultaneously
released under a Creative Commons Attribution Licence, which allows others to share the work, while acknowledging the original authorship
and initial publication in this Journal. The full licence notice is available at http://journal.embnet.org. 
hours (Iglowstein et al., 2003) of sleep per day. During the transition from middle childhood to adolescence, a gradual delay in the start time of sleep, as well as changes in the starting time between weekdays and weekends and longer sleep duration on weekends are observed. These changes in sleep habits have become more pronounced in recent years, with an emphasis on the transition from childhood to adolescence (Bayer et al., 2007). More specifically, studies show that as the age increases from school to adolescence, the duration of sleep decreases (without it meaning that the needs decrease), usually due to delayed onset of sleep and forced waking up early in the morning (Owens et al., 2008). Sleep deprivation at this age is due in large part to a delay in the onset of adolescent sleep and waking up too early for school. In Greece, there is a large percentage of adolescents who complain of unsatisfactory sleep, more girls than boys (Lazaratou et al., 2008). According to the literature, most adolescents sleep later than they should due to reading, social life and use of electronic media, and get up early in the morning (Alfano et al., 2010). A survey in Britain found that $30 \%$ of 15 -year-old boys and $49 \%$ of 15 -year-old girls report sleep problems and $36 \%$ of all 15-year-olds report not getting enough sleep to cope with school obligations (Bruce et al., 2017). Lack of sleep leads to drowsiness during the day (Dewald et al., 2010) that causes problems in the adolescent's cognitive skills, response to school and reading, and also in behaviour, risk-taking and emotional stability (anxiety, depression etc.) (Roberts et al., 2009). Poor sleep hygiene in the form of the use of digital media (TV, mobile, computer) predicts a delay in bedtime, reduced sleep duration, increased daytime sleepiness and even nightmares (Hale and Guan, 2015; Eggermont and Van den Bulck, 2006; Higuchi et al., 2005). The theory that the use of these media results in the development of sleep disorders is based on exposure to stimulating light, the content of the media (e.g. thrillers increase arousal), as well as the time consumed by the use of digital media (Foerster et al., 2019). As for adolescents with anxiety disorder, they may rely on digital media to avoid the onset of sleep or forget their worries. However, research shows that anxious teens spend more time watching television than healthy teens because they see it as a means of coping with stress (De Wit et al., 2011). The literature has reported a poor relationship between sleep hygiene and sleep problems (Mindell et al., 2009; LeBourgeois et al., 2005). However, there is a lack of extensive research regarding the relationship between sleep hygiene and its disorders in adolescents with anxiety disorders.

The association of sleep disorders with anxiety disorders in adolescents is a research topic of many studies in the recent years to understand if anxiety disorders cause sleep disorders and vice versa. The presence of an anxiety disorder causes a sleep problem, while the presence of a sleep disorder can subsequently cause an anxiety disorder (Sarchiapone et al., 2014). Even in young people, a large percentage that shows symptoms of an anxiety disorder also has problematic sleeping habits (Telzer et al., 2014). Children and adolescents with anxiety disorders tend to have a threat bias, and at the same time show an increased tendency to view dubious situations as threatening (Barrett et al., 1996; Blossom et al., 2013). In addition, adolescents with anxiety disorders have elevated cortisol levels at bedtime compared to groups of healthy adolescents (Forbes et al., 2006). Indeed, cortisol is associated with arousal, and high levels of arousal around bedtime result in delayed onset (Hatzinger et al., 2012).

The aim of this study was the cultural adaptation and validation of the Adolescent Sleep Hygiene Scale (ASHS), a tool that measures sleep hygiene, in an adolescent sample living in Greece.

\section{Materials, Methodologies and Techniques}

\section{Participants}

The study sample was recruited from the tertiary Center for Adolescent Medicine and UNESCO Chair on Adolescent Health Care of the First Department of Pediatrics at the Aghia Sophia Children's Hospital in Athens, Greece. To determine a sample size sufficient for factor analytic procedures, the following two criteria were used: (i) the sample should have 51 more cases than the number of variables to support chi-square testing in Bartlett's test of sphericity (Lawley and Maxwell, 1971; Gorsuch, 1983), (ii)the sample should include at least 100 cases and the subjects to variables (STV) ratio should be no less than 5 (Suhr, 2006; Hatcher, 1994).

\section{Inclusion and exclusion criteria}

Teenagers, 12- to 18-years of age, able to read and write in Greek, were eligible to participate in the study. Adolescents with major psychiatric disorders or other chronic diseases known to affect sleep, and substance users were excluded.

Adolescents and their parents or guardians were informed about the purpose of the study and signed consent forms prior to study entry. The study protocol was approved by the ethics committee of the Aghia Sophia Children's Hospital. The entire survey (translation, pilot, and main study) was conducted from December 2017 to December 2018.

\section{Validation Procedure}

Trying to achieve an excellent and unbiased translation for the instrument, multiple techniques were used as proposed for cross-cultural research, namely forward translation, backward translation, expert committee review and preliminary pilot testing (Tsang et al., 2017; Hallet al., 2018). During the forward translation procedure, two bilingual (Greek and English) translators worked independently to produce a Greek version of the ASHS. Some minor discrepancies among the two translators were resolved by an independent reviewer. 
During the backward translation procedure, the version that was produced in the previous step was back translated in English by two bilingual translators experienced in the target culture and who had never seen before the original English version of the scale. Following this, a source-language questionnaire developer highlighted each word or phrase that was discrepant. An expert committee that included a member with indepth knowledge of adolescent health and an expert in research methodology and translation process, solved some minor discrepancies and a consensus was reached. Examining feasibility was the last stage of the crosscultural adaptation process before producing the final version of the Greek version of ASHS. A group that included eight healthy adolescents, aged 12-18 years, was recruited to contribute to the preliminary pre-testing of the translated version and to ensure the original instructions, items and scoring materials were clearly expressed. The last step of pilot testing involved the questionnaire completion with an aim to explore how adolescents interacted and completed the instrument.

Twenty adolescents were recruited to pilot testing of the investigated tool. This step provided an opportunity to investigate the wording of the instructions, the understanding of the items, and the way of completion with the provided response scale. Moreover, in this stage, there was an opportunity of recording the time that participants needed to fill in the questionnaire.

\section{Materials}

Study participants were asked about their demographic characteristics, as well as to complete the following two tools:

Adolescent Sleep Hygiene Scale (ASHS): The Adolescent Sleep Hygiene Scale (ASHS) was initially constructed by LeBourgeois (LeBourgeois et al., 2005) and was modified from the Children's Sleep Hygiene Scale (Harsh et al., 2002). The ASHS is a 28-item selfreport tool that assesses sleep-facilitating and sleepinhibiting practices in 12- to 18-year-old adolescents along 9 different conceptual domains: physiological (5 items), cognitive (6 items), emotional (3 items), sleep environment (4 items), daytime sleep (1 item), substances (2 items), bedtime routine (1 item), sleep stability (4 items), and bed/bedroom sharing (2 items) (LeBourgeois et al., 2005). Participants report how often behaviours related with sleep hygiene have occurred during the past months using a 6-point Likert scale (1="always," 2="frequently-if not always," 3="quite often," $4=$ "sometimes," $5=$ "once in a while," $6=$ "never").The original measure had a good reliability index and more specifically the Cronbach's Alpha reliability index for the scales that make it up ranged from 0.46 to 0.74 for the areas of sleep hygiene, and 0.80 for the whole scale (total ASHS) (LeBourgeois et al., 2005).

Adolescent Stress Questionnaire (ASQ): The Adolescent Stress Questionnaire (ASQ) consists of 58 questions related to the stress of the adolescent in the last year (Byrne et al., 2007). The ASQ has been translated and validated in the Greek population (Darviri et al., 2017). The 58 items in the Greek validation were categorised into 10 conceptual areas: stress of home life (12 items), school performance (7 items), school attendance (3 items), romantic relationships (5 items), peer pressure (7 items), teacher interaction (7 items), future uncertainty (3 items), school/leisure conflict (5 items), financial pressure (4 items), and emerging adult responsibility (3 items). The Greek validation showed a good reliability index and, more specifically, Cronbach's alpha internal consistency for the mentioned scales ranged from 0.70 to 0.86 and was equal to 0.96 for the whole scale (total ASQ) (Darviri et al., 2017). The present study showed a good internal consistency and, in particular, Cronbach's alpha for ASQ scales ranged from 0.66 to 0.90 .

\section{Statistical analysis}

Data analysis was conducted using the SPSS statistical software version 25 (IBM Corp. Released 2017. IBM SPSS Statistics for Windows, Version 25.0. Armonk, NY: IBM Corp.). All variables of the study were calculated with descriptive analyses including mean, standard deviation (SD), absolute and relative frequencies. Exploratory Factor Analysis (EFA) with a Varimax rotation was conducted. Internal consistency was assessed using Cronbach's alpha. Convergent validity was examined by undertaking Spearman rho correlation.

Table 1. Demographic characteristics of study participants.

\begin{tabular}{ll}
\hline Characteristics & Total sample (N=146) \\
\hline Gender & $\mathbf{N}(\%)$ \\
\hline Male & $51(34.9)$ \\
\hline Female & $95(65.1)$ \\
\hline Educational Stage & $91(62.3)$ \\
\hline Junior High School & $55(37.7)$ \\
\hline High School & \\
\hline Maternal Education level & $62(42.5)$ \\
\hline Up to secondary & $58(39.7)$ \\
\hline University degree & $26(17.8)$ \\
\hline Postgraduate studies & \\
\hline Paternal Education level & $65(44.5)$ \\
\hline Up to secondary & $54(37.0)$ \\
\hline University degree & $27(18.5)$ \\
\hline Postgraduate studies & Mean \pm SD \\
\hline & $14.43 \pm 1.90$ \\
\hline Age (years) & \\
Qualitative variables are presented as absolute and relative frequencies \\
and quantitative variable (age) as mean \pm standard deviation (SD).
\end{tabular}


Table 2. Exploratory factor analysis of items of Adolescent Sleep Hygiene Scale (ASHS) after varimax rotation using principal components $(\mathrm{N}=146)$.

\begin{tabular}{|c|c|c|c|c|c|c|c|c|c|}
\hline & \multicolumn{9}{|c|}{ Factors } \\
\hline & 1 & 2 & 3 & 4 & 5 & 6 & 7 & 8 & 9 \\
\hline \multicolumn{10}{|l|}{ Psychological } \\
\hline $\begin{array}{l}\text { After 6:00 pm, I have drinks with caffeine (for example: cola, pop, root } \\
\text { beer, iced tea, coffee). }\end{array}$ & -0.051 & 0.188 & 0.676 & 0.130 & 0.210 & 0.226 & 0.047 & 0.111 & 0.001 \\
\hline $\begin{array}{l}\text { During the } 1 \text { hour before bedtime, I am very active (for example: } \\
\text { playing outside, running, wrestling). }\end{array}$ & -0.125 & 0.142 & 0.094 & 0.012 & 0.006 & 0.723 & -0.193 & -0.007 & 0.085 \\
\hline $\begin{array}{l}\text { During the } 1 \text { hour before bedtime, I drink }>4 \text { glasses of water (or some } \\
\text { other liquid). }\end{array}$ & 0.117 & -0.078 & 0.032 & 0.058 & 0.020 & 0.787 & 0.053 & 0.002 & -0.164 \\
\hline I go to bed with a stomachache. & 0.446 & 0.017 & -0.137 & -0.077 & 0.582 & 0.012 & -0.130 & 0.182 & -0.010 \\
\hline I go to bed feeling hungry. & 0.076 & 0.155 & 0.207 & 0.002 & 0.597 & -0.181 & -0.066 & -0.054 & -0.229 \\
\hline \multicolumn{10}{|l|}{ Cognitive } \\
\hline $\begin{array}{l}\text { During the } 1 \text { hour before bedtime, I do things that make me feel very } \\
\text { awake (for example: playing video games, watching television, talking } \\
\text { on the telephone). }\end{array}$ & 0.074 & 0.728 & -0.072 & 0.192 & 0.007 & 0.055 & 0.123 & 0.049 & 0.075 \\
\hline $\begin{array}{l}\text { I go to bed and do things in my bed that keep me awake (for example: } \\
\text { watching television, reading). }\end{array}$ & 0.085 & 0.596 & 0.228 & 0.425 & 0.140 & -0.073 & -0.152 & 0.184 & 0.238 \\
\hline I go to bed and think about things I need to do. & 0.711 & 0.020 & 0.269 & 0.245 & 0.008 & -0.053 & 0.036 & 0.039 & 0.072 \\
\hline I go to bed and replay the day's events over and over in my mind. & 0.795 & 0.013 & -0.053 & 0.117 & -0.056 & 0.137 & 0.190 & 0.026 & 0.021 \\
\hline $\begin{array}{l}\text { I use my bed for things other than sleep (for example: talking on the } \\
\text { telephone, watching television, playing video games, doing homework). }\end{array}$ & 0.103 & 0.537 & 0.170 & 0.372 & 0.059 & 0.196 & 0.164 & -0.082 & -0.090 \\
\hline I check my clock several times during the night. & 0.116 & 0.680 & 0.107 & -0.122 & 0.024 & -0.070 & 0.130 & -0.009 & -0.060 \\
\hline \multicolumn{10}{|l|}{ Emotional } \\
\hline $\begin{array}{l}\text { During the } 1 \text { hour before bedtime, things happen that make me feel } \\
\text { strong emotions (sadness, anger, excitement). }\end{array}$ & 0.528 & 0.536 & 0.067 & -0.144 & 0.213 & 0.080 & 0.035 & -0.124 & 0.010 \\
\hline I go to bed feeling upset. & 0.480 & 0.386 & 0.170 & -0.190 & 0.214 & -0.042 & -0.022 & -0.038 & -0.129 \\
\hline I go to bed and worry about things happening at home or at school. & 0.703 & 0.323 & 0.117 & -0.187 & 0.106 & -0.110 & -0.102 & 0.055 & -0.108 \\
\hline \multicolumn{10}{|l|}{ Sleep environment } \\
\hline I fall asleep while listening to loud music. & 0.042 & 0.133 & 0.079 & 0.570 & 0.052 & 0.027 & 0.103 & 0.005 & -0.319 \\
\hline I fall asleep while watching television. & -0.009 & 0.066 & 0.024 & 0.794 & 0.044 & 0.000 & 0.083 & -0.172 & -0.085 \\
\hline $\begin{array}{l}\text { I fall asleep in a brightly lit room (for example, the overhead light is } \\
\text { on). }\end{array}$ & -0.245 & -0.046 & -0.039 & 0.383 & 0.499 & 0.190 & 0.144 & -0.158 & 0.069 \\
\hline I fall asleep in a room that feels too hot or too cold. & -0.055 & 0.290 & 0.337 & 0.234 & 0.432 & 0.023 & 0.247 & 0.027 & -0.369 \\
\hline \multicolumn{10}{|l|}{ Daytime sleep } \\
\hline During the day I take a nap that lasts $>1$ hour. & 0.203 & -0.054 & 0.367 & -0.013 & 0.494 & 0.303 & 0.078 & -0.072 & 0.200 \\
\hline \multicolumn{10}{|l|}{ Substances } \\
\hline After 6:00 pm, I smoke or chew tobacco. & 0.203 & 0.086 & 0.641 & -0.146 & 0.055 & -0.104 & 0.200 & -0.079 & -0.359 \\
\hline After 6:00 pm, I drink beer (or other drinks with alcohol). & 0.143 & 0.061 & 0.784 & 0.079 & 0.040 & -0.010 & -0.011 & 0.027 & 0.053 \\
\hline \multicolumn{10}{|l|}{ Bedtime routine } \\
\hline I use a bedtime routine (for example, bathing, brushing teeth, reading). & -0.018 & 0.070 & 0.007 & -0.195 & -0.017 & -0.071 & 0.061 & -0.063 & 0.773 \\
\hline \multicolumn{10}{|l|}{ Sleep stability } \\
\hline During the school week, I stay up $>1$ hour past my usual bedtime. & 0.002 & 0.288 & 0.195 & 0.174 & 0.462 & 0.046 & 0.320 & 0.054 & 0.302 \\
\hline During the school week, I "sleep in" >1 hour past my usual wake time. & 0.080 & -0.065 & 0.445 & 0.424 & -0.023 & 0.299 & 0.108 & 0.072 & 0.223 \\
\hline On weekends, I stay up $>1$ hour past my usual bedtime. & 0.083 & 0.194 & 0.026 & 0.178 & 0.016 & -0.052 & 0.714 & -0.090 & 0.067 \\
\hline On weekends, I "sleep in" >1 hour past my usual wake time. & 0.009 & 0.048 & 0.105 & 0.011 & 0.024 & -0.051 & 0.763 & 0.172 & -0.038 \\
\hline \multicolumn{10}{|l|}{ Bed/Bedroom sharing } \\
\hline I sleep alone. & 0.040 & -0.101 & 0.087 & 0.037 & -0.043 & -0.123 & 0.006 & 0.868 & 0.036 \\
\hline $\begin{array}{l}\text { I sleep all or part of the night with someone else (for example, with } \\
\text { your parent[s], sister, or brother). }\end{array}$ & -0.030 & -0.173 & 0.019 & 0.313 & -0.034 & -0.180 & -0.132 & -0.716 & 0.129 \\
\hline Loadings & 2.60 & 2.56 & 2.29 & 2.13 & 1.78 & 1.61 & 1.57 & 1.50 & 1.38 \\
\hline Variance explained & 9.28 & 9.13 & 8.17 & 7.59 & 6.34 & 5.75 & 5.59 & 5.34 & 4.93 \\
\hline
\end{tabular}

Five factors explaining 62.1\% of the total variance; Kaiser-Meyer-Olkin $(K M O)=0.700$; Bartlett's Test of Sphericity: $p<0.001$. Bold values indicate factor loading of greater than 0.3. Cronbach's alpha of total scale: $a=0.78$. 
Table 3. Correlations between the Adolescent Sleep Hygiene Scale (ASHS) and Adolescent Stress Questionnaire (ASQ) scales.

\begin{tabular}{|c|c|c|c|c|c|c|c|c|c|c|}
\hline & $\begin{array}{l}\text { Stress of } \\
\text { Home } \\
\text { Life }\end{array}$ & $\begin{array}{l}\text { Stress of } \\
\text { School } \\
\text { Perfor- } \\
\text { mance }\end{array}$ & $\begin{array}{l}\text { Stress of } \\
\text { School } \\
\text { Attend- } \\
\text { ance }\end{array}$ & $\begin{array}{l}\text { Stress of } \\
\text { Romantic } \\
\text { Relation- } \\
\text { ships }\end{array}$ & $\begin{array}{l}\text { Stress } \\
\text { of Peer } \\
\text { Pressure }\end{array}$ & $\begin{array}{l}\text { Stress of } \\
\text { Teacher } \\
\text { Interac- } \\
\text { tion }\end{array}$ & $\begin{array}{l}\text { Stress of } \\
\text { Future } \\
\text { Uncer- } \\
\text { tainty }\end{array}$ & $\begin{array}{l}\text { Stress of } \\
\text { School/ } \\
\text { Leisure } \\
\text { Conflict }\end{array}$ & $\begin{array}{l}\text { Stress of } \\
\text { Financial } \\
\text { Pressure }\end{array}$ & $\begin{array}{l}\text { Stress of } \\
\text { Emerging } \\
\text { Adult } \\
\text { Responsi- } \\
\text { bility }\end{array}$ \\
\hline Psychological & $0.228^{* *}$ & -0.024 & $0.167^{\star}$ & $0.199^{*}$ & 0.026 & 0.099 & 0.118 & 0.159 & $0.188^{*}$ & $0.201^{*}$ \\
\hline Cognitive & $0.427^{\star * *}$ & $0.330^{* * *}$ & $0.338^{* * *}$ & $0.275^{\star *}$ & $0.344^{* * *}$ & $0.282^{\star *}$ & $0.453^{* * *}$ & $0.312^{\star * *}$ & $0.305^{* * *}$ & $0.284^{\star *}$ \\
\hline Emotional & $0.461^{* * *}$ & $0.392^{* * *}$ & $0.369^{* * *}$ & $0.331^{* * *}$ & $.407^{* * *}$ & $0.212^{*}$ & $0.422^{* * *}$ & $0.331^{* * *}$ & $0.333^{* * *}$ & $0.207^{*}$ \\
\hline $\begin{array}{l}\text { Sleep environ- } \\
\text { ment }\end{array}$ & $0.169^{*}$ & 0.054 & $0.224^{\star *}$ & $0.250^{\star *}$ & 0.158 & $0.232^{\star *}$ & $0.205^{*}$ & $0.165^{\star}$ & $0.183^{*}$ & 0.154 \\
\hline Daytime sleep & $0.194^{*}$ & 0.137 & $0.175^{*}$ & $0.275^{\star *}$ & 0.113 & $0.173^{*}$ & $0.176^{*}$ & $0.198^{*}$ & $0.184^{*}$ & $0.232^{* *}$ \\
\hline Substances & $0.273^{* *}$ & $0.202^{*}$ & $0.240^{* *}$ & $0.341^{* * *}$ & $0.188^{*}$ & 0.085 & $0.342^{* * *}$ & 0.148 & $0.335^{* * *}$ & $0.275^{\star *}$ \\
\hline Bedtime routine & 0.045 & -0.053 & 0.082 & 0.091 & 0.066 & -0.053 & -0.026 & -0.020 & 0.018 & -0.077 \\
\hline Sleep stability & $0.224^{* *}$ & 0.136 & $0.246^{* *}$ & $0.204^{*}$ & 0.142 & $0.176^{*}$ & $0.244^{* *}$ & 0.147 & $0.231^{\star *}$ & $0.178^{*}$ \\
\hline $\begin{array}{l}\text { Bed/Bedroom } \\
\text { sharing }\end{array}$ & 0.000 & 0.013 & -0.028 & 0.004 & 0.078 & 0.075 & 0.035 & 0.047 & -0.012 & 0.112 \\
\hline
\end{tabular}

**** $p<0.001 ; * * 0<0.01 ; * p<0.05$ (Spearman rho correlation coefficients).

\section{Results}

\section{Pilot study}

Upon completion of the translation procedure, a pilot study was conducted among 20 adolescents. There was no difficulty by the students in completing the tool, neither in marking nor in the questions. The reliability index in the pilot study was found to be equal to Cronbach's $\alpha$ $=0.73$ and was considered satisfactory (Houser, 2008).

\section{Main study}

The sample of the main study consisted of 146 Greek adolescents. Descriptive statistics of the demographic and other characteristics of the sample are presented in Table 1.

About 2 of 3 participants were female (65.1\%) and $34.9 \%$ of the participants were males. The majority of the sample was studying in junior high school (62.3\%) and $37.7 \%$ in high school. The maternal education level was up to secondary level for $42.5 \%$ of the participants mothers, $39.7 \%$ had university degrees and $17.8 \%$ had postgraduate studies. The paternal education level was up to secondary level for $44.5 \%$ of the participants' mothers, $37.0 \%$ had university degrees and $18.5 \%$ had postgraduate studies. The age of participants ranged from 12 to 18 years with a mean age of 14.43 years $(\mathrm{SD}=1.90)$, which also was gender-matched $(\mathrm{p}=0.650)$.

Factor analysis was performed, and the initial nine factors were extracted (Table 2). The total variance explained by EFA was found as $62.1 \%$. The internal consistency of the Greek version of ASHS carried out using Cronbach's alpha coefficient was $\alpha=0.77$ for the total scale.

The Psychological scale was split into two factors indicating that the construct validity of this scale was not supported totally. The first item about drinking caffeine in the afternoon did not load better to this factor, but it was loaded in the factor with other substances. The other two items in the Substances scale (tobacco and alcohol drinks) matched perfectly into the same factor. Cognitive scales' items were divided in two factors (two out of six loaded in other factors). The Emotional scale's item perfectly loaded in the initial component. Three out of four items of the Sleep Environment scale loaded together in one factor, except for the item "I fall asleep in a room that feels too hot or too cold" which loaded higher in other factors. The Daytime scale had only one item which consisted the fifth component of the table. Three out of four items of the Sleep Stability scale loaded together in one factor, except for the item "During the school week, I "sleep in" >1 hour past my usual wake time" which loaded higher in other factors. The last scale of Bed/Bedroom Sharing was extracted in one factor with the last item showing a negative load which indicated reverse item.

\section{Convergent validity}

To prove convergent validity, Spearman's correlation coefficients were calculated between ASHS and ASQ scales. Positive but not strong correlations were found between these two tools. Strongest correlations were found between Emotional (ASHS) and Stress of Home Life (ASQ) $\left(r_{s}=0.461, p<0.001\right)$ (Table 3).

\section{Discussion}

The aim of the present study to validate the ASHS was accomplished as confirmatory and reliability analyses were supportive of a valid tool, whileour findings were comparable with other studies that have used this measure (Galland et al., 2017; de Bruin et al., 2014; Alfiyah et al., 2018). The main difference proposed in this 
study is the item concerning caffeine to be moved to the Substance use scale.

In young people, a large percentage with symptoms of an anxiety disorder also have problematic sleep habits (Telzer et al., 2014). One of the main lifestyle factors that affect adolescence is sleep, while adolescents tend to sleep late and want to stay up late, even on weekdays (Kirov et al., 2017). The transition from childhood to adolescence affects a young person in many areas of life and to a great extent. Teenagers' feelings and the way they experience the changes in their life are more intense, therefore they experience the stress that these changes can bring to a greater degree. Research conducted in America has shown that adolescent sleep is also affected by the situation at home, such as stress and parental depression (Schmeer et al., 2018). The same result was found in the present study where stress factors caused by living at home significantly affected sleep habits, i.e. it was found that as stress due to the teenager's home increases, so does poor sleep hygiene. Our results demonstrated a statistically significant correlation between stress and sleep quality in adolescents.

In conclusion, the Greek version of the ASHS constitutes a valid measure of the adolescent sleep hygiene, as the tool allows adolescents to report their own sleep-facilitating and sleep-inhibiting practices, adding to current knowledge and aiding future research in the field of adolescent health.

\section{Key Points}

- Sleep is one of the major lifestyle factors that affects adolescent physical and mental health.

- The Adolescent Sleep Hygiene Scale (ASHS) was validated in an adolescent sample living in Greece.

- ASHS is a reliable and valid tool for evaluating sleep-facilitating and sleep-inhibiting practices of Greek adolescents.

\section{References}

1. Alfano C, Pina A, Zerr A, Villalta I (2010) Pre-sleep arousal and sleep problems of anxiety-disordered youth. Child Psychiatry Hum Dev 41, 156-167. http://dx.doi.org/10.1007/s10578-0090158-5

2. Alfiyah SN, Sri F, Yudianto K (2018) Adolescent Moslem Students Sleep Hygiene Behaviour Description At Pondok Pesantren. JNC 1(1).

3. Barrett PM, Rapee RM, Dadds MM, Ryan SM (1996) Family enhancement of cognitive style in anxious and aggressive children. J Abnorm Child Psychol 24, 187-203. http://dx.doi. org/10.1007/BF01441484

4. Bayer JK, Hiscock H, Hampton A, Wake M (2007) Sleep problems in young infants and maternal mental and physical health. J Peadiatr Child Health 43(1-2), 66-73. http://dx.doi.org/10.1111/ j.1440-1754.2007.01005.x

5. Blossom JB, Ginsburg GS, Birmaher B, Walkup JT, Kendall PC et al. (2013) Parental and family factors as predictors of threat bias in anxious youth. Cogn Therapy Res 37, 812-819. http://dx.doi. org/10.1007/s10608-012-9513-0

6. Bruce ES,Lunt L, McDonagh JE (2017) Sleep in adolescents and young adults. Clinical Medicine 17(5), 424-428. http://dx.doi. org/10.7861/clinmedicine.17-5-424

7. Byrne DG, Davenport SC, Mazanov J (2007) Profiles of adolescent stress: the development of the Adolescent Stress Questionnaire
(ASQ). Journal of Adolescence 30(3), 393-416. http://dx.doi. org/10.1016/j.adolescence.2006.04.004

8. Darviri C, Legaki PE, Chatzioannidou P, Gnardellis C, Kraniotou C et al. (2017) Adolescent Stress Questionnaire: Reliability and validity of the Greek version and its description in a sample of high school (lyceum) students. Journal of Adolescence 37(8), 1373-1377. http://dx.doi.org/10.1016/j.adolescence.2014.10.003

9. de BruinEJ, van Kampen RKA, van Kooten T, Meijer AM (2014) Psychometric properties and clinical relevance of the Adolescent Sleep Hygiene Scale in Dutch adolescents. Sleep Medicine 15(7), 789-97. http://dx.doi.org/10.1016/j.sleep.2014.03.015

10. De Wit L, van Straten A, Lamers F, Cuijpers P, Penninx B (2011) Are sedentary television watching and computer use behaviors associated with anxiety and depressive disorders? Psychiatry Res 186(2-3), 239-243. http://dx.doi.org/10.1016/j. psychres.2010.07.003

11. Dewald JF, Meijer AM, Oort FJ, Kerkhof GA, Bögels SM (2010) The influence of sleep quality, sleep duration and sleepiness on school performance in children and adolescents: a metaanalytic review. Sleep Med Rev 14(3), 179-189. http://dx.doi. org/10.1016/j.smrv.2009.10.004

12. Drummond SPA, Brown GG, Stricker JL, Buxton RB, Wong EC et al. (1999) Sleep deprivation-induced reduction in cortical functional response to serial subtraction. NeuroReport 10(18), 3745-3748. http://dx.doi.org/10.1097/00001756-19991216000004

13. Eggermont S, Van den Bulck J (2006) Nodding off or switching off? The use of popular media as a sleep aid in secondary-school children. J Paediatr Child Health 42(7-8), 428-33. http://dx.doi. org/10.1111/j:1440-1754.2006.00892.x

14. Foerster M, Henneke A, Chetty-Mhlanga S,Röösli M (2019) Impact of Adolescents' Screen Time and Nocturnal Mobile Phone-Related Awakenings on Sleep and General Health Symptoms: A Prospective Cohort Study. Int J Environ Res Public Health 16(3), 518. http://dx.doi.org/10.3390/ijerph16030518

15. Forbes EE, Williamson DE, Ryan ND, Birmaher B, Axelson DA et al. (2006) Peri-sleep-onset cortisol levels in children and adolescents with affective disorders. Biol Psychiatry 59(1), 24-30. http://dx.doi.org/10.1016/j.biopsych.2005.06.002

16. Galland BC, Gray AR, Penno J, Smith C, Lobb C et al. (2017) Gender differences in sleep hygiene practices and sleep quality in New Zealand adolescents aged 15 to 17 years. Sleep Health 3(2), 77-83. http://dx.doi.org/10.1016/j.sleh.2017.02.001

17. Gorsuch RL (1983) Factor analysis (2nd ed.). Hillsdale, NJ: Erlbaum.

18. Hale L and Guan S (2015) Screen Time and Sleep among School-Aged Children and Adolescents: A Systematic Literature Review. Sleep Med Rev 21, 50-58. http://dx.doi.org/10.1016/j. smrv.2014.07.007

19. Hall DA, Zaragoza Domingo S, Hamdache LZ, Manchaiah V, Thammaiah S et al. (2018) A good practice guide for translating and adapting hearing-related questionnaires for different languages and cultures. International Journal of Audiology 57(3), 161-175. http://dx.doi.org/10.1080/14992027.2017.1393565

20. Harsh JR, Easley A, LeBourgeois MK (2002) An instrument to measure children's sleep hygiene [abstract]. Sleep 25, A316.

21. Hatcher L (1994) A Step-by-Step Approach to Using the SAS System for Factor Analysis and Structural Equation Modeling. Cary, NC: SAS Institute, Inc.

22. Hatzinger M, Brand SB, Perren S, vonWyl A, Stadelmann S et al. (2012) Pre-schoolers suffering from psychiatric disorders show increased cortisol secretion and poor sleep compared to healthy controls. J Psychiatric Res 46(5), 590-9. http://dx.doi. org/10.1016/j.jpsychires.2012.01.018

23. Higuchi S, Motohashi Y, Liu Y, Maeda A (2005) Effects of playing a computer game using a bright display on presleep physiological variables, sleep latency, slow wave sleep and REM sleep. J Sleep Res 14(3), 267-73. http://dx.doi.org/10.1111/j.13652869.2005.00463.x

24. Houser J (2008) Precision, reliability, and validity: Essential elements of measurement in nursing research. J Spec Pediatr 
Nurs 13(4), 297-299. http://dx.doi.org/10.1111/j.17446155.2008.00171.x

25. Iglowstein I, Jenni OG, Molinari L, Largo RH (2003) Sleep duration from infancy to adolescence: reference values and generational trends. Pediatrics 111(2), 302-307. http://dx.doi. org/10.1542/peds.111.2.302

26. Kirov R, Brand S, Banaschewski T, Rothenberger A. (2017) Opposite impact of REM sleep on neurobehavioral functioning in children with common psychiatric disorders compared to typically developing children. Front Psychol 7, 2059. http:// dx.doi.org/10.3389/fpsyg.2016.02059

27. Lawley DN, Maxwell AE (1971) Factor analysis as a statistical method. Butterworths.

28. Lazaratou E, Dikeos D, Anagnostopoulos D, Soldatos C (2008) Habits and problems of sleep in adolescent students. Psychiatriki 19, 221-230.

29. LeBourgeois MK, Giannotti F, Cortesi F, Wolfson A, Harsh J (2005) The relationship between reported sleep quality and sleep hygiene in Italian and American adolescents. Pediatrics 115(1 Suppl), 257-65. http://dx.doi.org/10.1542/peds.2004-0815H

30. Mindell JA, Meltzer LJ, Carskadon MA, Chervin RD (2009) Developmental aspects of sleep hygiene: findings from the 2004 National Sleep Foundation Sleep in America Poll. Sleep Med 10(7), 771-9. http://dx.doi.org/10.1016/j.sleep.2008.07.016

31. Muzur A, Pace-Schott EF, Hobson JA (2002) The prefrontal cortex in sleep. Trends in Cognitive Sciences 6(11), 475-481. http://dx.doi.org/10.1016/s1364-6613(02)01992-7.

32. Nielsen TA, Laberge L, Paquet], Tremblay RE, Vitaro F et al. (2000) Development of Disturbing Dreams During Adolescence and Their Relation to Anxiety Symptoms. Sleep 23(6):727-36.

33. Owens J (2008) Classification and Epidemiology of Childhood Sleep Disorders. Prim Care 35(3), 533-46, vii. http://dx.doi org/10.1016/j.pop.2008.06.003
34. Roberts RE, Roberts CR, Duong HT (2009) Sleepless in adolescence: prospective data on sleep deprivation, health and functioning. J Adolesc 32(5), 1045-1057. http://dx.doi. org/10.1016/j.adolescence.2009.03.007

35. Sarchiapone M, Mandelli L, Carli V, Iosue M, Wasserman C (2014) Hours of sleep in adolescents and its association with anxiety, emotional concerns, and suicidal ideation. Sleep Med 15(2):248-54. http://dx.doi.org/10.1016/j.sleep.2013.11.780

36. Schmeer KK, Tarrence J, Browning CR, Calder CA, Ford JL (2018) Family contexts and sleep during adolescence. SSM Popul Health 7, 004-4. http://dx.doi.org/10.1016/j.ssmph.2018.11.004

37. Suhr DD (2006) "Exploratory or confirmatory factor analysis?" Retrieved 28 November 2020 from http://www2.sas.com/ proceedings/sugi31/200-31.pdf.

38. Talbot LS, McGlinchey EL, Kaplan KA, Dahl RE, Harvey AG (2010) Sleep Deprivation in Adolescents and Adults: Changes in Affect. Emotion 10(6), 831-41. http://dx.doi.org/10.1037/ a0020138

39. Telzer EH, Fuligni AJ, Lieberman MD, Galván A (2014) The effects of poor quality sleep on brain function and risk taking in adolescence. Neuroimage 71, 275-83. http://dx.doi.org/10.1016/j. neuroimage.2013.01.025

40. Tsang S, Royse CF, Terkawi AS (2017) Guidelines for developing, translating, and validating a questionnaire in perioperative and pain medicine. Saudi J Anaesth 11(Suppl 1), S80-S89. http:// dx.doi.org/10.4103/sja.SJA 203_17

41. Wang Y, Ralfed MR, Slopen N, Hale L, Dunn EC (2016) Childhood adversity an insomnia in adolescent. Sleep Med 21, 12-8. http:!/! dx.doi.org/10.1016/j.sleep.2016.01.011

42. Yoo S, Gujar N, Hu P, Jolesz FA, Walker MP (2007) The human emotional brain without sleep-a prefrontal amygdala disconnect. Current Biology 17(20), R877-8. http://dx.doi.org/10.1016/j. cub.2007.08.007 